\title{
Ranking periodic ordering models on the basis of minimizing total inventory cost
}

\author{
Mohammadali Keramati $^{\mathrm{a}}$ and Vahid Bahmani ${ }^{\mathbf{b}}$
}

${ }^{a}$ Assistant proffessor, Arak Branch, Islamic Azad University, Arak, Iran

${ }^{b}$ Departement of System Management \& Productivity, Arak Branch, Islamic Azad University, Arak, Iran

\section{H R O N I C L E}

Article history:

Received January 20, 2015

Received in revised format 16

February 2015

Accepted 9 April 2015

Available online

April 92015

Keywords:

Ranking periodic order models

Inventory costs

Simulating annealing

LTC

\section{A B S T R A C T}

This paper aims to provide proper policies for inventory under uncertain conditions by comparing different inventory policies. To review the efficiency of these algorithms it is necessary to specify the area in which each of them is applied. Therefore, each of the models has been reviewed under different forms of retailing and they are ranked in terms of their expenses. According to the high values of inventories and their impacts on the costs of the companies, the ranking of various models using the simulation annealing algorithm are presented, which indicates that the proposed model of this paper could perform better than other alternative ones. The results also indicate that the suggested algorithm could save from 4 to 29 percent on costs of inventories.

\section{Introduction}

In explaining the supply chain, one may describe it as a process and people who are involved in fulfilling customers' needs directly or indirectly. Generally a supply chain consists of five steps including the customers, the retailers, the wholesalers/ distributers, the producers and the suppliers of primary equipment (Chopra \& Meindel, 2007). The primary objective of the supply chain management is to build an authentic flow in transferring the material and the services from the beginning to the end of the supply chain. The entire factors required to be authentic include the quality, the quantity, the cost and the delivery time (Hajshirmohammadi, 2008). Having an integrated chain of supply which can deliver the material needed for the final customer adequately and in proper time and place and with the lowest price is considered as the most important objective of the supply chain (Graves \&Willems, 2000). Some people estimate that the cost to keep the inventory in every situation is between 20 to 40 percent of the total inventory, annually. Nevertheless, keeping the inventory is essential to increase the level of services to customers and also to decrease the distribution costs (Bollou, 1992). Since every member of the chain faces its general problems, for having a smooth flow of materials there must be a

\footnotetext{
E-mail address: v.bahmani@ymail.com (V. Bahmani) 
balance on the inventory to prevent any possible shortage while we minimize the inventory. In other words, the inventory must be managed the way to minimize the costs and the confidence on delivery system would not be distracted, simultaneously (Suri, 1998). Thus, this paper compares different periodic order models including the Periodic order Quantity (POQ), the Least Total Cost (LTC), The Least Unit Cost (LUC), Silver-Meal (SM), Wagner Within (WW), and the Lot for Lot (LFL), using the suggested simulating model on the basis of the total cost of the inventory in a three level distributing supply chain including the suppliers, distributors and the producers.

The inventories consist of the primary elements, unfinished items, spare wares and the product through which the correct control can be effective in balancing the present operations. Also making more reliable, dynamic and durable planning against changes plays essential role on having stable supply chain (Muller, 2003). There are also some expenses associated with inventory such as the costs for the lost opportunities, the storage costs, the tax cost, the insurance, etc. On the other hand there are important factors, which lead the tendency of management to care more about the preserving such as giving fast services to the customers, the decrease in the cost of giving orders, benefiting the workforce and the equipment properly, the decrease in transportation costs and the decline in paying to the supplier (AlamTabriz \& Sobhanifard, 2013).

To analyze the inventory control system, it is necessary to recognize the inventory costs. In terms of managing and controlling the inventory the main objectives of the management of an organization is to develop the policies, which can minimize the operational costs. Therefore, the managers try to involve a desired amount of financial resources with inventories to make a balance between the costs. As a whole, different types of costs can be divided in four groups including the storage and the preservation costs, the order, installment and initiation costs, the shortage costs and the purchase costs (in case there is a discount) (Hosseini-Baharanchy, 2002).

\section{Periodic order models}

To review and to determine the best operation between the inventory management methods, primarily it is necessary to give a definition.

\subsection{Lot for lot (LFL) method}

LFL is a method for lot sizing, where the system regards the net requirements placed for each period as an order quantity. This method is implemented where the maintenance cost is higher than registration and order cost (Khademizarea, 2004). LFL policy minimizes the stock in the storage and thus helps economize on maintenance costs. Nonetheless, order (preparation) costs will be relatively high in this policy due to the great number of orders (Hajshirmohammadi, 2008).

\subsection{Periodic order quantity (POQ) method}

In this method, the quantity of orders is equal to the consumption of a number of future periods. The consumption of these periods approximately corresponds to the quantity of economic order obtained from the well-known economic order quantity (EOQ). POQ is a model with the best overall performance.

\subsection{Least unit cost (LUC) method}

In this method, the quantity of orders is equal to the demand of one or more future periods. The quantity of orders and the number of periods that each order covers is not fixed. In this method it is assumed that the use of the stock occurs at the beginning of each period (New, 1975). 


\subsection{Least total cost (LTC) method}

In this method, the quantity of orders is the same as the demand for one or more future periods. The quantity of orders is determined in a way that the ordering costs per unit as is kept, as much as possible, close to the cost of maintenance per unit of products (Dematteis, 1968).

\subsection{Least period cost (LPC)}

In this method, the quantity of orders is chosen in a way that the same characteristic of EOQ method for regular demand is repeated, that is, in a way that the total cost per time unit is minimized for the duration that the order covers (Silver \& Meal, 1973). It is shown Silver-Mill method generally operates better than the least unit cost (Baker, 1989).

\subsection{Wagner-Within (WW) Algorithm}

This algorithm, which is designed based on dynamic programming, is an optimization technique. This method aims to investigate the consumptions of all the periods of planning vision at each period and makes decisions based on the terms of planning horizon. Obviously, the number of possible combinations increases with an increase in the number of planning vision programs. In this method, it is assumed that the shortage of stock is not permitted and the initial stock is zero (Wagner \& Within, 1985; Kulkarni \& Rajhans, 2013).

Considering the existing studies there has been no ranking for the periodical ordering models, which makes the present paper new in this term. To do so it is necessary to introduce the most famous models and policies of the inventory management and specify the objectives and approaches for each one. Afterwards, the approaches expected in this area must be extracted and finally considering such elements the new methods in this area must be introduced and analyzed. Fig. 1 shows the process of the research:

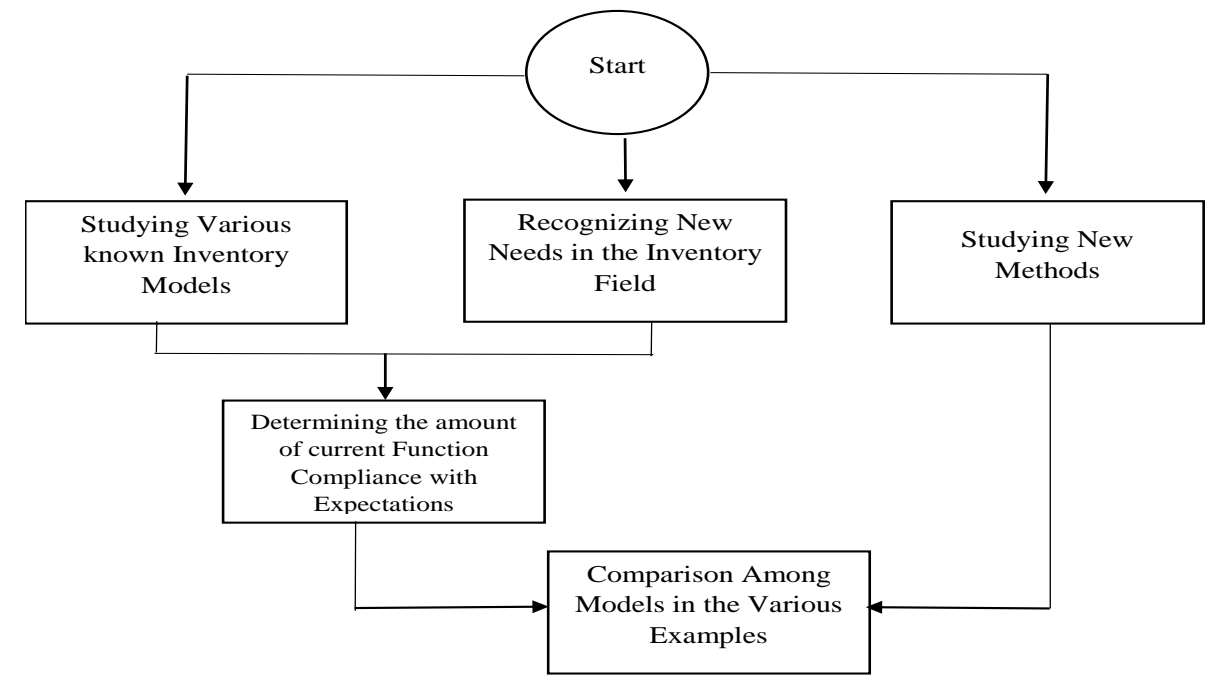

Fig. 1. The process of the research

These areas will be reviewed and introduced following.

\section{The methodology and modeling}

\subsection{Method}

This research can be counted as of the applied ones in terms of objective and library based in terms of data collection method and in terms of the kind it is classified on the basis of quantitative studies. 


\subsection{Reviewing the methods in the existence of a distributor}

The data related to 8 items of the inventory are achieved via simulating method from article (Bai \& Liu, 2014). But because of the randomness of the parameters of the issue, Monte Carlo simulation is used in order to create data.

\section{Table 1}

The data of the selected items existed

\begin{tabular}{ll}
\hline Item & Data \\
\hline The item with the highest annual value & 141349769 \\
The item with the lowest annual value & 185286 \\
The item with the highest annual consumption & 2000 \\
The item with the lowest annual consumption & 18 \\
The item with the highest cost unit & 72001.63275 \\
The item with the lowest cost unit & 360.6395806 \\
The item with the most delivery date (days) & 9 \\
The item with the least delivery date (days) & 3 \\
\hline
\end{tabular}

\section{Table 2}

The characteristics of simulating

\begin{tabular}{cccc}
\hline Characteristics number & Statistics type & Number in each simulation & Simulations number \\
\hline 5 & Average & 25 & 12 \\
\hline
\end{tabular}

As can be seen from Table 2, the 5 main features of each order which must identically exist in different ordering models and supply must be in average as a result of 12 simulations where in each one 25 averages have been simulated. The significant note is that to perform each average correctly the random average has been used.

\subsection{The supply chain modeling}

In this research, a supply chain is introduced by considering uncertain demands and the characteristics of the supply chain is as follows:

A three-level supply chain includes the suppliers, the producers and also the distributors which must review different demands in various regions. It is also possible that demand was not met and also goods would be postponed for the next period. Also there is no transportation possibility between the producing centers and every producer center must only use its own store for preserving and also during the planning it cannot change its inventory policy. The costs related to orders, holding costs and ordering are of the most crucial parameters during the issue. On the basis of this model, the possibility to compare different models of the order and the inventory preserving has been provided. The following mathematical model starts with introducing the variables and the parameters and then introduces the mathematical modeling.

\section{Table3}

Indexes, parameters and variables

\begin{tabular}{ll}
\hline Indexes & \\
\hline$i$ & The displayer of the chosen ties as hub \\
$j$ & The displayer of not chosen ties as hub \\
\hline Parameters & \\
\hline Demand $_{j, b}$ & Demand of point $b$ from point $j$ which is a periodical and unreliable parameter \\
\hline Variables & \\
\hline$D_{i}$ & The maximum capacity of the hub point $i$ to transfer the demand \\
$Z_{i}$ & If the tie $i$ is chosen as hub \\
$x_{i, j}$ & If the $j$ tie is connected to $i$ hub and is the only transfer way for $j$ \\
$x_{i, j, s, b}$ & If the transfer existis between the two non-hub ties $i, j$ from the two middle group $i$ and $s$ \\
\hline
\end{tabular}


The mathematical model of this research is as follows:

$\min \varphi$

subject to

$$
\begin{array}{lc}
x_{i, j} \leq Z_{i} & \forall i, j \\
Z_{i} \leq \sum_{j} x_{i, j} & \forall i \\
x_{i, j, s, b} \leq x_{i, j} x_{s, b} & \forall i, j, s, b \\
\sum_{j} \sum_{b} \sum_{s \neq b} x_{i, j, s, b} \text { Demand }_{j, b} \leq D_{i} & \forall i \\
\sum_{j} \sum_{b} \sum_{s \neq b} x_{i, j, s, b} \text { Demand }_{j, b} \leq D_{s} & \forall s \\
\widetilde{\operatorname{Cr}}\left\{\sum_{i} \sum_{j} \sum_{b} \sum_{s \neq b} x_{i, j, s, b} \text { Demand }_{j, b} \leq \varphi\right\} \geq \alpha & \\
x_{i, j}, Z_{i} x_{i, j, s, b} \in\{0,1\} &
\end{array}
$$

In this model, the primary objective is minimization of all intra-hub transformations in the chain. The constraint number 1 guarantees that the tie $j$ can be transferred to hub $i$, in case when the hub $i$ is formed and in other words if $Z_{i}=1$, therefore $i$ may belong to $j$. In the constraint number 2, if at least one attribution of non-hub points like $j$ belongs to $i, \sum_{j} x_{i, j}$ then we can consider this capable of becoming a hub, which means $Z_{i}=1$ or $Z_{i}=0$. The constraint number 3 guarantees that the transformation between the two hubs $i$ and $s$ for the demand $j$ and $b$ is possible when $j$ belongs to $i$ and $b$ belongs to $s$. The constraint 4 and 5 also guarantee that while this transformation happens, the capacities of the points of the hubs $i$ and $s$ are not complied with. The constraint number 6 also specifies that there is an amount of $\varphi$ which is maximum for such transformations in credibility function and this amount must decrease as much as possible and also it must be higher than the minimum amount of $\alpha$. In better words, the credibility function tends to enhance the amount of existing conflicts in different demands moving and between the alpha must go higher than an expected amount, Eq. (1) and Eq. (2) specify the relationships of this function in two general and specific modes for this issue. The constraint number 7 also specifies the kind of the variables in this question.

The credibility function is generally defined as follows:

$$
\widetilde{C r}\{\xi \leq r\}=0.5\left(\operatorname{Sup}_{x \in R} \mu(x, \tilde{\theta})+\operatorname{Sup}_{x \leq r} \mu(x, \tilde{\theta})-\operatorname{Sup}_{x>r} \mu(x, \tilde{\theta})\right.
$$

On this basis, considering the amount $\alpha \in(0,1)$, the main objective of the issue can be stated as follows:

$$
\min \left\{\varphi \mid \widetilde{\operatorname{Cr}}\left\{\sum_{i} \sum_{j} \sum_{b} \sum_{s \neq b} x_{i, j, s, b} \text { Demand }_{j, b} \leq \varphi\right\} \geq \alpha\right.
$$

Therefore we have:

$\min \varphi$

subject to

$\widetilde{\operatorname{Cr}}\left\{\sum_{i} \sum_{j} \sum_{b} \sum_{S \neq b} x_{i, j, s, b}\right.$ Demand $_{j, b} \leq \varphi$ 


\section{The solution}

To study the behavior of the suggested algorithm in a chain some second-step elements (distributers) of a three level chain was reviewed. The proposed method specifies which way each distributer in the chain uses to manage its inventory. Note that as evident in the elements of the model and on the basis of distribution and the supply chain it can be stated that the transfers have been executed in a level which is between the hubs and the distributors. In other words, all transfers are in the level of distributors, some of which are hubs and some are only the points to offer services to the customers and is excused in the hub viewpoint. In this part the way to implement the simulation algorithm is explained for the issue. The algorithm starts with a primary answer which is generated randomly and ends with an ending condition. The ending condition for the algorithm is to perform 100 continuous repetition of the algorithm. Table 4 demonstrates the results of our survey for single distributing mode.

\section{Table 4}

Ranking the order models

\begin{tabular}{ccccc}
\hline method & cost & $\begin{array}{c}\text { Difference with the } \\
\text { previous rating }\end{array}$ & difference with the best & $\begin{array}{c}\text { difference with the } \\
\text { worst }\end{array}$ \\
\hline SA & 451792872 & 1 & 0 & 0.28576 \\
LTC & 475103765 & 0.04906 & -0.051596416 & 0.2488 \\
POQ & 497376872 & 0.04478 & -0.100895793 & 0.21358 \\
WW & 508679255 & 0.02222 & -0.125912529 & 0.19571 \\
SM & 591295445 & 0.13972 & -0.308775507 & 0.06508 \\
LFL & 606198552 & 0.02458 & -0.341762098 & 0.04152 \\
LUC & 632457596.9 & 0.04152 & -0.399883965 & 0 \\
\hline
\end{tabular}

As can be seen in Table 4, the proposed simulated annealing method (SA) performs better than other seven methods in terms of cost. The $4^{\text {th }}$ column in Table 4 shows the percentage of the difference of each method compared with the other methods (in terms of rank). As an example, the percentile difference for the method, the total cost, is calculated as follows:

$\frac{\text { Cost }_{\text {LTC }}-\text { Cost }_{S A}}{\operatorname{Cost}_{\text {LTC }}}=\frac{475103765-451792872}{475103765}=0.049064846$

Reviewing the numbers of the fourth column, it is clarified that the most difference is between the two continuous ranks related to the percentile difference of the method, the total cost, compared with the suggested algorithm.

The fifth column of this table shows the percentile difference of the cost achieved from every method compared with the best way or the proposed method. As an instance for the criteria, the economical number is calculated as follows:

$\frac{\text { Cost }_{S A}-\text { Cost }_{P O Q}}{\text { Cost }_{S A}}=\frac{451792872-497376872}{451792872}=-0.100895793$

The numbers in this column are in subtractive mode, in other words, by increasing the ranking of the presented methods the gap with the SA are widen. Also note that the negative digits do not show the error percentage and show the difference between models and the algorithms only. In the sixth column of this table the percentile difference has been shown through the worst way or as it is called the unit cost way. As an example this principle has been calculated as following for Wagner and Within method:

$\frac{\text { Cost }_{L U C}-\text { Cost }_{W W}}{\operatorname{Cost}_{L U C}}=\frac{632457596.9-508679255}{632457596.9}=0.195710104$

According to Fig. 2 SA has presented the least and the unit cost method has offered the most cost. 


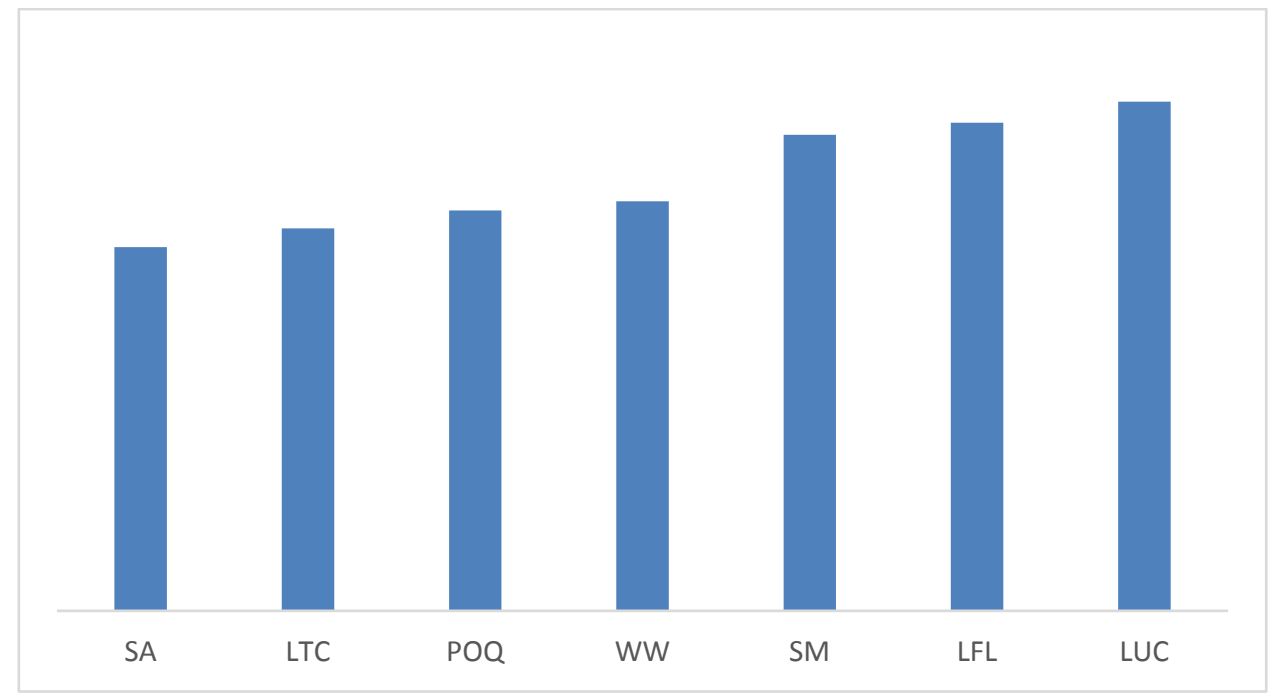

Fig. 2. The amount of costs between different methods

\subsection{In supply chain mode}

Since the proposed method of this paper is formulated as mixed integer programming, it is necessary to use the meta-heuristic method introduced to find near optimal solutions. In this survey, we use Matlab R 2013a. After optimization, the evaluation principle for each sample questions is as follows:

- For the issues of 30 demand points, the equality of the answers has been achieved using the two mentioned algorithm for all 15 tested samples.

- For the issues of 60 demand points, among 15 solved questions, twelve of them are binding. For the rest of the questions the lower bounds have been achieved via critical way method and the evaluation principle is the deviation from this amount.

On the one hand, the data of this research has been created and analyzed on the basis of random digit creation. Also the summary of the results and figures of comparing the function of simulating algorithm for all questions are given in Table 5 and note that the costs are at million. In addition Fig. 3 demonstrates the comparison between the best answers and the worst answers and the average of the result of each method in 30-distributor mode and 60-distributor mode has been presented:

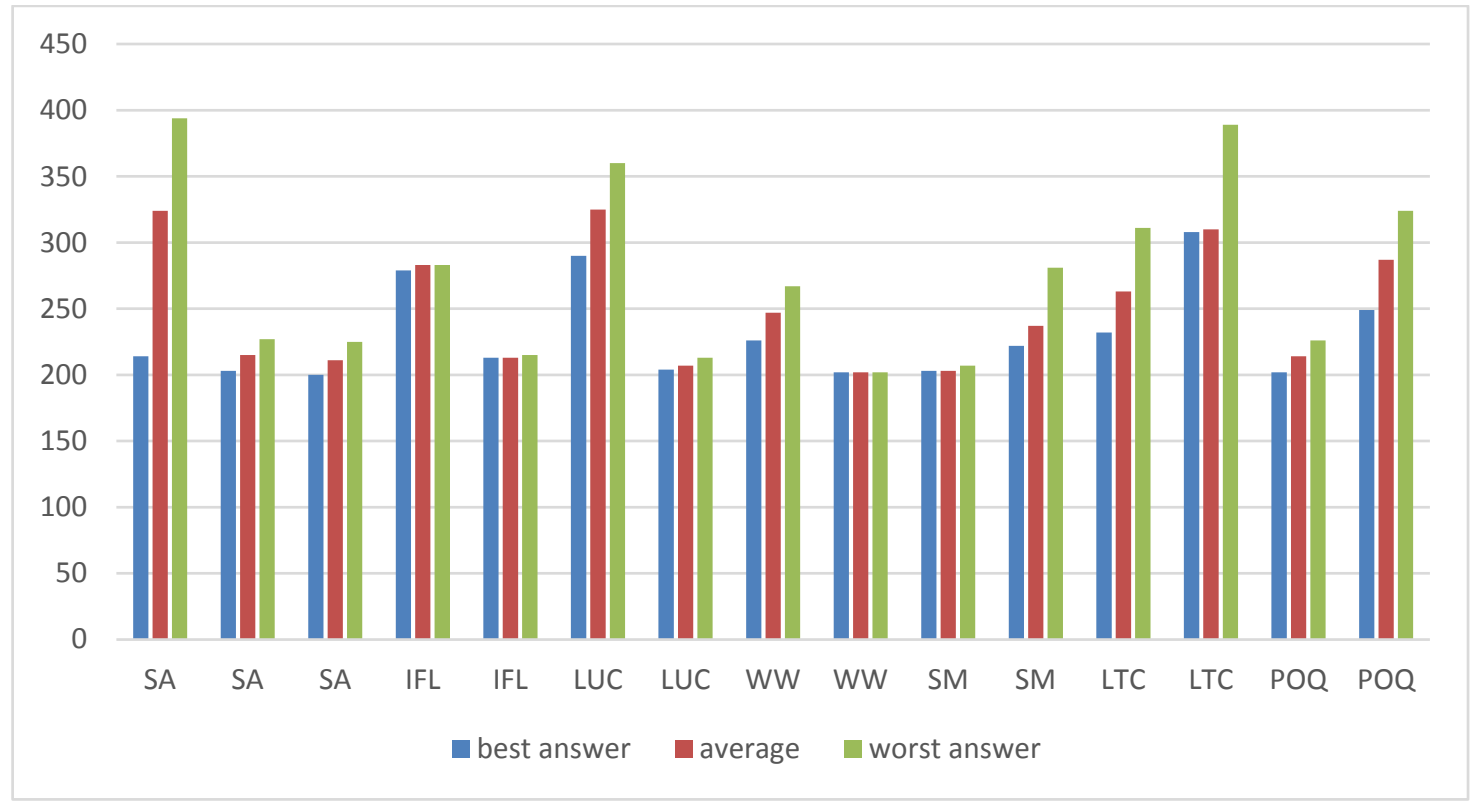

Fig. 3. The comparison chart for 30 distributors 
Table 5

Comparing the models in supply chain

\begin{tabular}{|c|c|c|c|c|c|c|}
\hline \multicolumn{3}{|c|}{ Question size } & \multicolumn{3}{|c|}{ Simulation algorithm } & \multirow{2}{*}{$\begin{array}{c}\text { Inventory } \\
\text { policy }\end{array}$} \\
\hline Distributor numbers & demander & Hub & best answer & average & worst & \\
\hline \multirow{15}{*}{30 distributor } & 35 & 3 & 214 & 324 & 394 & \multirow{3}{*}{ SA } \\
\hline & 37 & 3 & 203 & 215 & 227 & \\
\hline & 39 & 3 & 200 & 211 & 225 & \\
\hline & 32 & 3 & 279 & 283 & 283 & \multirow{2}{*}{ LFL } \\
\hline & 33 & 3 & 213 & 213 & 215 & \\
\hline & 34 & 3 & 290 & 325 & 360 & \multirow{2}{*}{ LUC } \\
\hline & 43 & 5 & 204 & 207 & 213 & \\
\hline & 44 & 5 & 226 & 247 & 267 & \multirow{2}{*}{ WW } \\
\hline & 45 & 5 & 202 & 202 & 202 & \\
\hline & 43 & 5 & 203 & 203 & 207 & \multirow{2}{*}{ SM } \\
\hline & 49 & 5 & 222 & 237 & 281 & \\
\hline & 42 & 5 & 232 & 263 & 311 & \multirow{2}{*}{ LTC } \\
\hline & 66 & 8 & 308 & 310 & 389 & \\
\hline & 62 & 8 & 202 & 214 & 226 & \multirow{2}{*}{ POQ } \\
\hline & 63 & 8 & 249 & 287 & 324 & \\
\hline \multirow{15}{*}{60 distributor } & 63 & 5 & 223 & 322 & 363 & \multirow{3}{*}{ SA } \\
\hline & 64 & 5 & 277 & 280 & 382 & \\
\hline & 67 & 5 & 223 & 223 & 225 & \\
\hline & 62 & 5 & 345 & 346 & 383 & \multirow{2}{*}{ LFL } \\
\hline & 69 & 5 & 322 & 322 & 327 & \\
\hline & 63 & 5 & 213 & 218 & 219 & \multirow{2}{*}{ LUC } \\
\hline & 65 & 8 & 201 & 234 & 255 & \\
\hline & 62 & 8 & 291 & 296 & 303 & \multirow{2}{*}{ WW } \\
\hline & 61 & 8 & 380 & 392 & 392 & \\
\hline & 81 & 10 & 331 & 333 & 393 & \multirow{2}{*}{ SM } \\
\hline & 84 & 10 & 224 & 227 & 229 & \\
\hline & 85 & 10 & 345 & 364 & 395 & \multirow{2}{*}{ LTC } \\
\hline & 86 & 10 & 275 & 365 & 392 & \\
\hline & 87 & 10 & 264 & 291 & 297 & \multirow{2}{*}{ POQ } \\
\hline & 82 & 10 & 227 & 252 & 345 & \\
\hline
\end{tabular}

According to Fig. 3 and Fig. 4, the best answers in sample issues have been the same for different algorithms, therefore, the suggested algorithm has a usual function compared with other competitors in the chain. 


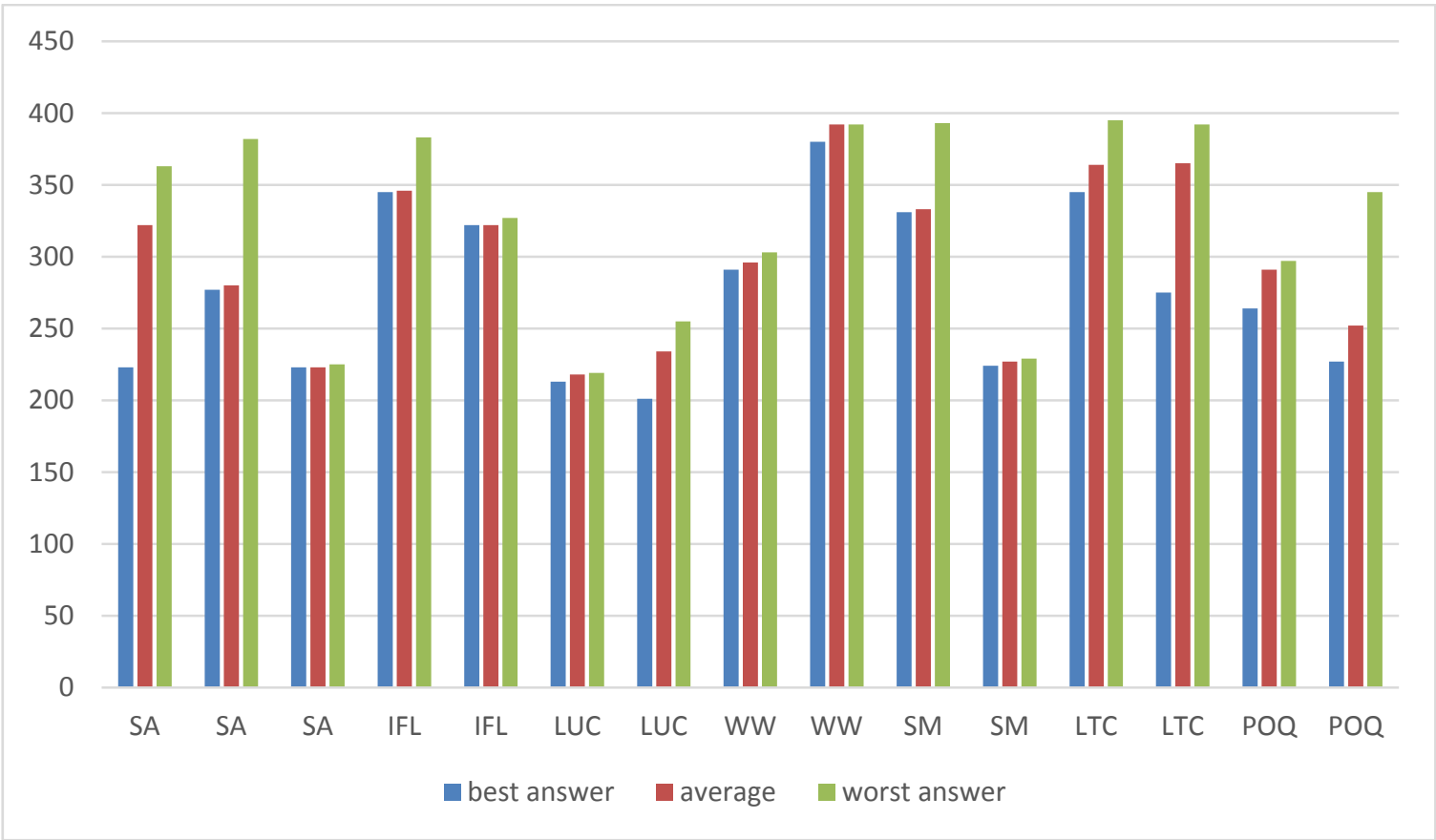

Fig. 4. The comparison chart for 60 distributors

\section{Conclusion}

The main objective in managing the supply chain is to make a trustworthy flow in transferring the material and the services from the beginning to the end of the supply chain, keeping the inventory in order to increase the level of services and decreasing the production costs. The inventories have to be managed to minimize the costs and to optimize the other indexes such as ensuring delivery system in supply chain. Therefore, in this research the models of periodical orders including POQ, LTC, LTC, LUC, SM, WW and FL have been considered using the suggested simulation algorithm on the basis of minimizing the total inventory costs and improving the target function in a supply chain aiming to create a hub. Hence, to review the presented methods there was a three-level supply chain presented by 30 and 60 distributors and the results for each model of periodical order have been compared with each other using the simulation algorithm. In this comparison as it was obvious the best answers in sample issues perform the same for different algorithms. Although most modern ways have been offered such as the ways presented by Samak-Kulkarni and Rajhans (2013) the proposed model of this paper has been able to do better compared with other similar ways of inventory management.

\section{Acknowledgement}

The authors would like to thank the anonymous referees for constructive comments on earlier version of this paper.

\section{References}

Alam tabriz, A., \& Sobhani fard, Y. (2013). Production and Operations Management. Tehran: academic book publishing (In Persian).

Bai, X., \& Liu, Y. (2014). Robust optimization of supply chain network design in fuzzy decision system. Journal of Intelligent Manufacturing, 1-19.

Baker, K. R. (1989). Lot-sizing procedures and a standard data set: a reconciliation of the literature. Journal of Manufacturing and Operations Management, 2(3), 199-221.

Bollou, R.H. (1992). Business Logistics Management. $3^{\text {rd }}$ ed., prentice- Hall, Englewood, Clios, NJ. 
Samak-Kulkarni, S. M., \& Rajhans, N. R. (2013). Determination of Optimum Inventory Model for Minimizing Total Inventory Cost. Procedia Engineering, 51, 803-809.

Chopra, S., \& Meindel, P. (2007). Supply chain management. $3^{\text {rd }}$ edition. New York: Prentice Hall.

DeMatteis, J. J. (1968). An economic lot-sizing technique, I: The part-period algorithm. IBM systems Journal, 7(1), 30-38.

Graves, S. C., \& Willems, S. P. (2000). Optimizing strategic safety stock placement in supply chains. Manufacturing \& Service Operations Management,2(1), 68-83.

Hajshirmohammadi, A. (2008). Principles of production and inventory planning and control. (In Persian).

Hosseini-Baharanchy, S. R. (2002). Production planning and inventory control and order. Tehran: Jam Jam world Publications (In Persian).

Khademi zarea, H. (2004). Comprehensive approach to inventory control. Tehran: knowledge Soroush publishing (In Persian).

Muller, M. (2003). Essentials of Inventory management. American management Association (AMACOM).

New, C. (1975). Safety stocks for requirements planning. Production and Inventory Management, 16(2), 1-18.

Orlicky, J. (1975). Material requirements planning. McGrawHill. New York.

Samak-Kulkarni, S. M., \& Rajhans, N. R. (2013). Determination of Optimum Inventory Model for Minimizing Total Inventory Cost. Procedia Engineering, 51, 803-809.

Suri, R. (1998). Quick response manufacturing: a companywide approach to reducing lead times. Productivity Press.

Silver, E. A., \& Meal, H. C. (1973). A heuristic for selecting lot size quantities for the case of a deterministic time-varying demand rate and discrete opportunities for replenishment. Production and inventory management, 14(2), 64-74.

Wagner, H. M., \& Whitin, T. M. (1958). Dynamic version of the economic lot size model. Management science, 5(1), 89-96. 